\title{
Research Paper: Comparing Time-Use Estimates of Two Different Time Diary Methods
}

\author{
Hossein Sourtiji ${ }^{1,2} \mathbb{C}$, Mehdi Rassafiani ${ }^{3,4}$, Seyed Ali Hosseini ${ }^{1,5^{*}} \mathbb{C}$, Mohammad Esmaeil Motlagh ${ }^{6}$, Mehdi Noroozi ${ }^{7} \mathbb{C}$
}

1. Department of Occupational Therapy, University of Social Welfare and Rehabilitation Sciences, Tehran, Iran.

2. Department of Occupational Therapy, School of Rehabilitation Sciences, Isfahan University of Medical Sciences, Isfahan, Iran

3. Department of Occupational Therapy, Faculty of Allied Health Sciences, Kuwait University, Kuwait City, Kuwait.

4. Pediatric Neurorehabilitation Research Center, University of Social Welfare and Rehabilitation Sciences, Tehran, Iran.

5. Social Determinants of Health Research Center, University of Social Welfare and Rehabilitation Sciences, Tehran, Iran.

6. Department of Pediatrics, Faculty of Medical, Ahvaz Jundishapur University of Medical Sciences, Ahvaz, Iran

7. Substance Abuse and Dependence Research Center, University of Social Welfare and Rehabilitation Sciences, Tehran, Iran.

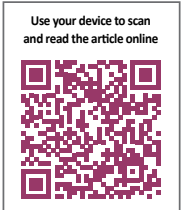

Citation Sourtiji H, Rassafiani M, Hosseini SA, Motlagh ME, Noroozi M. Comparing Time-Use Estimates of Two Different Time Diary Methods. Iranian Rehabilitation Journal. 2018; 16(4):387-394. http://dx.doi.org/10.32598/irj.16.4.387

: http://dx.doi.org/10.32598/irj.16.4.387

Article info:

Received: 25 Apr 2018

Accepted: 10 Aug 2018

Available Online: 01 Dec 2018

\section{Keywords:}

Time-use, Yesterday-diary, Tomorrow-diary, Children

\section{ABSTRACT}

Objectives: Time-use has become an important field of research in social and medical sciences. Time diary is the most popular method for measuring time-use that has 2 different methods of administration including yesterday and tomorrow diary. The present study aimed to compare these methods of measuring time-use.

Methods: This cross-sectional comparative study was conducted on 256 under 5-year-old healthy children that were selected using multistage stratified cluster sampling method in 2017. Data were analyzed using Kolmogorov-Smirnov Test, Pearson correlation coefficient, Spearman correlation coefficient, 2-way ANOVA, Independent t-test and Mann-Whitney U Test.

Results: Participants spent $1476.23 \mathrm{~min} / \mathrm{d}$ on aggregate daily occupations, according to the yesterday-diary estimate, and $1492.14 \mathrm{~min} / \mathrm{d}$ according to the tomorrow-diary. In one area of occupation, the yesterday and tomorrow diary estimates differed slightly. Two-way ANOVA found no significant interaction between diary method and age category $\left(\mathrm{F}_{5234}=1.222, \mathrm{P}=0.300\right)$ and no significant main effect of diary method $\left(\mathrm{F}_{1,234}=0.830\right)$. While, the ANOVA revealed a significant main effect for age category $\left(\mathrm{F}_{5,234}=4.91, \mathrm{P}=0.00\right)$. There were no significant mean differences in the number of occupational repertoires between the participants of yesterday and tomorrow diary groups. Likewise, there were no significant differences in the number of verbatim of the two groups.

Discussion: The findings of our study indicated no difference between yesterday and tomorrow diaries estimates in terms of measuring under 5-year-old children's time-use.

\section{* Corresponding Author:}

Seyed Ali Hosseini, PhD.

Address: Department of Occupational Therapy, University of Social Welfare and Rehabilitation Sciences, Tehran, Iran.

Tel: +98 (21) 88364227

E-mail:alihosse@gmail.com 


\section{Highlights}

- The tomorrow method of time-use dairy were slightly better than yesterday-diary approach in terms of aggregate time estimates for daily occupations.

- The mean number of occupational repertoires measured by yesterday-diary was a little higher than that obtained by tomorrow-diary approach.

- From the point of view of caregivers, time estimates of tomorrow-diaries have better quality and are more valid.

\section{Plain Language Summary}

In our research, time use is the amount of time a child uses for various activities throughout the day and night. In this study, two methods of administration of time-use diary were compared in terms of quality and quantity of data. We found that although the data from tomorrow method is slightly higher than yesterday method of diary, there is no significant difference between them. Our findings indicate that participants can choose one of the two diary methods. These findings are important in helping researchers decide on how to use the time use diary more appropriately.

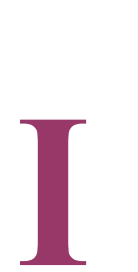

\section{Introduction}

$\mathrm{n}$ recent decades, there has been a growing interest in the study of time-use. Measurement of time-use in clinical practice is receiving interest, too $[1,2]$. Time-use studies provide information about the nature, duration, and context of all activities carried out by the people during a certain period of time [3-5].

Several methods for assessing time-use are available. These include time diary [3, 6, 7], the Experience Sampling Method (ESM) $[4,7,8]$, stylized approach [4, 9], and continuous observation $[8,10]$. Time diary is the most prevalent method as it has a higher level of validity and reliability [11]. Robinson (1999) suggested that time diaries can accurately represent an individual's behavior. All activities performed at a given time interval are recorded using time diary, along with a potentially rich array of contextual information, such as where and with whom they were performed, and whether they paid for it $[3,12]$.

Time diaries can be administered by 2 different methods of "tomorrow" and "yesterday" diaries. In the tomorrow-diary method that is also called "current", or "leftbehind" diary approach, interviewers leave time-use diaries behind for the participant to be completed after an initial face to face interview, on the following day(s). The interviewers will collect and check the time diaries at a time and place of participants' convenient [13-15].
In the "yesterday" or "retrospective" diary method, the respondent is required to recall recent events and record activities performed over a specified period that is usually yesterday. In other words, respondent recalls the activities of the past 24-hours. This method may also be administered via computer assisted telephone interviewing $[8,16]$.

These two methods of the time-use diary have some advantages and limitations. Tomorrow-diary is appropriate for participants with high literacy rates, and it is considered less intrusive, does not require the same level of recall ability as collecting data by an interview in yesterday-diary. It probes 5 to $10 \%$ more activities than yesterday-diary method. However, this method is not feasible for low-literate participants, is more expensive compared to yesterday-diary approach $[3,17,18]$, and is associated with a greater risk of social desirability effects [19].

On the contrary, yesterday-diary approach is very appropriate for low-literate participants and usually has a higher response rate. However, it has some limitations, including memory recall errors, normative editing, and underreporting of quick activities $[3,9,20]$. Considering these advantages and disadvantageous, the question is which method generates more valuable results. Some studies compared these 2 methods and demonstrated that both produced similar time-use estimates [21-23].

Tomorrow-diary method yields more events. However, research suggests that the difference in the number of events (an increase in the order of $10 \%$ ) fails to justify the additional cost of obtaining tomorrow's diaries [24- 
26]. In conclusion, the literature on these two methods of diaries are very limited, and there is no consensus on this method.

Time-use diary has received much attention by researchers as an instrument of data gathering in the field of time-use [27, 28]. However, only few studies have carefully assessed the relative strengths and weaknesses of the existing methods of measuring time-use [3, 13, 15]. These investigations compared diary estimates based on studies conducted many years ago [3, 20, 23]. Furthermore, previous studies compared the methods of administration of time-use diary in terms of adults [3, 24]. However, these studies overlooked children as the target population in this regard.

There is not enough available data to directly compare yesterday and tomorrow diary estimates for the children. Thus, such data are required to make an optimal diary approach selection. It is unclear that which time diary method is more applicable and economical. Therefore, the current study compared the two time-use methods of yesterday's and tomorrow diary approaches.

\section{Methods}

\section{Research design}

The present cross-sectional comparative study was conducted in the Takestan County, Qazvin Province, Iran, between May 22 and December 22, 2017.

\section{Sampling}

Using multistage stratified cluster sampling method, 256 under 5-year-old healthy children were recruited in the study. Children with severe mental or physical illnesses needing hostelry special care services (The children living in the institutions) were excluded from the research process.

The participants were selected from all regions of the county. In the first stage, representative areas were selected from similar socio-economic regions of urban and rural areas. Then, 7 rural health centers and 3 urban health centers were selected consisting of 16 rural health centers and 8 urban health centers. Subsequently, equal number of girls and boys were selected from various rural and urban healthcare centers based on the population density of children under 5 years old and in proportion to the number of children per each seven age groups (under 1 month, 2-3 months, 4-6 months, 7-12 months, 1-2 years, and 3-5 years).

\section{Research tools and procedures}

The version of the time-use diary that was applied in this research included 4 main open-ended questions on the beginning and end of primary activity. It also explored any other activities including where and with whom activities took place. The time-use diary which was either interviewer-administered or self-reported investigated the child's flow of activities over a 24-hour weekday period. We used an open response time-use diary and selected open interval via per 3 hours. Yesterdaydiaries were completed based on face to face interviews (and an additional phone interview as necessary). Also, tomorrow-diaries were left behind to main caregivers after a preparative interview. All data were gathered by 3 professionally trained staff that participated workshops about time-use mythology, administration of time-use diary and an interview method of assessment.

\section{Data analysis}

Contrary to previous time-use studies, in this study, tomorrow and yesterday diaries estimates of time-use were investigated based on 8 areas of occupations, which were classified based on the Occupational Therapy Practice Framework: Domain and Process, $3^{\text {rd }}$ Edition (OTPF3) [29]. Other indicators that were compared in this research included frequency of verbatim, occupational repertoire, co-occupations time estimates, and concurrent occupations time estimates.

The interpretation of the diaries were performed in several stages. In the first stage, verbatim was extracted and the number and duration of each were determined. In the next stage, the frequency and duration of the tasks, activities, and daily life occupations were determined according to the OTPF3. In the next stage, the time allocated to each area of occupations was determined based on the OFPF3. In addition, the number of occupations in occupational repertoire, the time allocated to the concurrent occupations, the time devoted to the child care activities (both interactive and physical child care) are specified.

Data were analyzed using Kolmogorov-Smirnov Test to check the normality assumption. Also, the Pearson correlation coefficient and Spearman correlation coefficient were applied to measure the association between variables. Two-way Analysis of Variance (ANOVA) in accordance with age category (under 3 months, 2-3 months, 4-6 months, 7-12 months, 13-24 months, 2560 months old), diary methods (yesterday and tomorrow diaries approaches), Independent samples t-test and 
Mann-Whitney U Test were used for the analysis of differences in SPSS.

\section{Results}

Table 1 lists descriptive data of respondents' time spent on daily occupations in a 'normal' weekday and weekend both for the total samples and for girls and boys, separately. On average, our respondents spend $1476.23 \mathrm{~min} / \mathrm{d}$ on daily occupations, according to the yesterday-diary estimate, and 1492.14 minutes according to the tomorrowdiary estimate. The yesterday and tomorrow diaries estimates significantly differed between girls and boys.

It may seem irrational that the average duration of daily occupations is more than 24 hours (1440 min). It can be explained that the duration of aggregate daily occupations is calculated by the sum of several areas of occupation, including activities of daily living, instrumental activities of daily living, rest and sleep, play, leisure, social participation, education and work. In addition, the times of play, leisure and social participation may have been calculated more than once and, the time of concurrent activities could have been considered more than once.

Table 2 presents separate tests for different age subgroups, indicating that the estimates of yesterday-diary significantly differed from that of tomorrow-diary. Table 3 indicates the time budgets for the areas of occupation. For the one area of occupation, the yesterday and tomorrodiary estimates differ only quite marginally. Thus, the differences observed between total occupation time were the result of summing up all the inconsistencies for the single areas of occupation that constitute total occupations.

Table 4 presents the number of occupational repertoires and verbatim results from yesterday and tomorrow diaries methods. Two-way ANOVA revealed no significant interac- tion between diary method and age category $\left(\mathrm{F}_{5,234}=1.222\right.$, $\mathrm{P}=0.300$ ) and no significant main effect of diary method $\left(\mathrm{F}_{1,234}=0.830\right)$. While, ANOVA suggested a significant main effect for age category $\left(\mathrm{F}_{5,234}=4.91, \mathrm{P}=0.00\right)$ (Table 5).

Table 6 indicates no significant mean differences in the number of occupational repertoires between the participants of yesterday and tomorrow diaries groups. Similarly, there was no significant differences in the number of verbatim between the two groups.

Using a phone interview, 60 participants (30 caregivers from each group), who were randomly selected, were asked of their perception about the quality of timeuse data (that they reported). In total, $50 \%$ of caregivers who participated in completing yesterday time use diary, described the quality of information as good, $23.33 \%$ described the quality of information as acceptable, and $26.67 \%$ described the quality of information as poor. While, of caregivers that completed tomorrow diary, $70 \%$ described the quality of information as good, $16.67 \%$ described the quality of information as acceptable and $13.33 \%$ described the quality of information as poor. In total, $16.15 \%$ of the participants in the tomorrow-diary group did not return the completed forms.

\section{Discussion}

The comparison of two administration methods of the time-use diary was the aim of the present study. The obtained results indicated that the estimates of tomorrow method of time-use dairy were slightly higher than yesterday-diary approach in terms of aggregate time estimates for daily occupations. However, this difference was not statistically significant. Although no differences were found between the estimates of two diary methods, there was a statistically significant difference between age categories in terms of daily occupations.

Table 1. Average time spent on daily occupations on 'normal' weekdays in minutes

\begin{tabular}{|c|c|c|c|c|c|c|}
\hline \multirow{3}{*}{$\begin{array}{l}\text { Descriptive } \\
\text { Statistics }\end{array}$} & \multicolumn{6}{|c|}{ Diary } \\
\hline & \multicolumn{2}{|c|}{ All } & \multicolumn{2}{|c|}{ Girls } & \multicolumn{2}{|c|}{ Boys } \\
\hline & Yesterday & Tomorrow & Yesterday & Tomorrow & Yesterday & Tomorrow \\
\hline Mean & 1476.23 & 1492.14 & 1469.73 & 1501.55 & 1482.41 & 1483.19 \\
\hline SD & 241.52 & 231.61 & 261.23 & 233.23 & 223.29 & 231.63 \\
\hline Correlation & \multicolumn{2}{|c|}{0.052} & \multicolumn{2}{|c|}{0.064} & \multicolumn{2}{|c|}{0.064} \\
\hline $\mathrm{n}$ & 115 & 119 & 56 & 50 & 59 & 61 \\
\hline
\end{tabular}


Table 2. Average time spent on daily occupations on 'normal' weekdays in minutes for age subgroups

\begin{tabular}{|c|c|c|c|c|}
\hline \multirow{2}{*}{ Age Groups } & \multicolumn{3}{|c|}{ Aggregate Occupations } & \multirow[b]{2}{*}{$\mathbf{n}$} \\
\hline & Variable & Mean & SD & \\
\hline \multirow{3}{*}{ Under 1 month } & Yesterday & 1292.86 & 80.45 & 7 \\
\hline & Tomorrow & 1272.43 & 107.58 & 7 \\
\hline & Total & 1282.64 & 91.88 & 14 \\
\hline \multirow{3}{*}{ 2-3 months } & Yesterday & 1473.33 & 182.55 & 6 \\
\hline & Tomorrow & 1262.5 & 134.72 & 8 \\
\hline & Total & 1352.86 & 185.24 & 14 \\
\hline \multirow{3}{*}{ 4-6 months } & Yesterday & 1394.67 & 102.36 & 6 \\
\hline & Tomorrow & 1541 & 285.47 & 8 \\
\hline & Total & 1478.29 & 231.43 & 14 \\
\hline \multirow{3}{*}{$7-12$ months } & Yesterday & 1490.19 & 220.7 & 16 \\
\hline & Tomorrow & 1434.29 & 145.22 & 18 \\
\hline & Total & 1460.65 & 183.86 & 34 \\
\hline \multirow{3}{*}{ 13-24 months } & Yesterday & 1432.11 & 193.09 & 27 \\
\hline & Tomorrow & 1482.09 & 285.88 & 22 \\
\hline & Total & 1454.55 & 237.87 & 49 \\
\hline \multirow{3}{*}{$25-60$ months } & Yesterday & 1528.28 & 284.78 & 53 \\
\hline & Tomorrow & 1567.95 & 205.62 & 56 \\
\hline & Total & 1548.66 & 246.93 & 109 \\
\hline \multirow{3}{*}{ Total } & Yesterday & 1476.23 & 241.52 & 115 \\
\hline & Tomorrow & 1492.14 & 231.61 & 119 \\
\hline & Total & 1484.32 & 236.16 & 234 \\
\hline
\end{tabular}

IIranian Rehabilitation Journal

Table 3. Average time spent on single area of occupations on 'normal' weekdays in minutes

\begin{tabular}{|c|c|c|c|c|c|}
\hline Component & Variable & Mean & SD & Correlation Coefficient & $\mathbf{n}$ \\
\hline \multirow[b]{2}{*}{ Activities of daily living } & Yesterday-diary & 221.65 & 67.123 & \multirow[b]{2}{*}{0.078} & 116 \\
\hline & & & & & 121 \\
\hline \multirow{2}{*}{ Instrumental activities of daily living } & Yesterday-diary & 45.47 & 46.212 & \multirow{2}{*}{-0.14} & 116 \\
\hline & Tomorrow-diary & 45.14 & 36.4 & & 119 \\
\hline \multirow{2}{*}{ Play } & Yesterday-diary & 241.04 & 110.702 & \multirow{2}{*}{-0.03} & 116 \\
\hline & Tomorrow-diary & 238.16 & 97.259 & & 121 \\
\hline \multirow{2}{*}{ Rest and sleep } & Yesterday-diary & 718.05 & 122.250 & \multirow{2}{*}{-0.071} & 116 \\
\hline & Tomorrow-diary & 699.90 & 107.633 & & 121 \\
\hline \multirow{2}{*}{ Leisure } & Yesterday-diary & 133.15 & 124.209 & \multirow{2}{*}{-0.048} & 116 \\
\hline & Tomorrow-diary & 140.62 & 110.630 & & 121 \\
\hline \multirow{2}{*}{ Social participation } & Yesterday-diary & 115.13 & 98.238 & \multirow{2}{*}{0.015} & 115 \\
\hline & Tomorrow-diary & 117.02 & 92.944 & & 121 \\
\hline
\end{tabular}


Table 4. Average number of occupational repertoires and verbatim on 'normal' weekdays

\begin{tabular}{cccccc}
\hline Component & Variable & Mean & SD & Correlation Coefficient & $\mathbf{n}$ \\
\hline \multirow{2}{*}{ Occupational repertoire } & Yesterday-diary & 13.06 & 3.937 & 0.026 & 116 \\
& Tomorrow-diary & 13.24 & 5.063 & & 121 \\
Verbatim & Yesterday-diary & 18.16 & 4.888 & -0.106 & 116 \\
& Tomorrow-diary & 18.18 & 6.654 & & 119 \\
\hline
\end{tabular}

Ilranian Rehabilitation Journal

Table 5. Two-way ANOVA results with factors of age category and diary method

\begin{tabular}{lccccc}
\hline & \multicolumn{1}{c}{ Tests of Between-Subjects Effects } & & & \\
\hline & Source & & df & F & Sig. \\
\hline \multirow{2}{*}{ Dependent variable: Occupations } & Diary & 1 & 0.046 & 0.83 \\
& Age_c & 5 & 4.91 & 0.00 \\
& Diary*age_c & 5 & 1.222 & 0.300 \\
\hline
\end{tabular}

*Design=diary-method age-categories diary*age_c

Ilranian Rehabilitation Dournal

These findings were consistent with Robinson (1985) that reported substantial similarity in time-use patterns based on yesterday and tomorrow diaries. However, the tomorrow-diaries captured 5 to $10 \%$ more activities compared to the yesterday-diaries $[3,24]$. The obtained results indicated the mean number of occupational repertoires measured by yesterday-diary was a little higher than those obtained by tomorrow-diary approach. while there was no significant differences between yesterday and tomorrow methods of the time-use diary in terms of the mean number of occupational repertoires and verbatim.

Results of phone interview about the quality of timeuse information revealed that from the point of view of caregivers, time estimates of tomorrow-diaries have better quality and are more valid. According to Robinson [24, 30] and Gershuny [18], recalling challenge is a serious treat to the quality of the estimates of yesterday time-use diary.
Our research clearly has some limitations. The most important limitation was the impossibility of administrating 2 methods of time-use diary of yesterday and tomorrow on a single group of participants. Additionally, we found that time-use data is age-related, therefore the findings might not be transferable to other age groups. We applied a novel method of time-use data coding based on OTPF, that have more sensitive definitions than other methods and can be more applicable in clinical settings [31]. No previous research has been done on the time-use of under 5-year-old children [31]. Thus, the results of this research can provide a basis for future studies in this field.

\section{Conclusion}

In conclusion, the present study revealed no differences between yesterday and tomorrow diary estimates for measuring under 5-year-old children's time-use. This suggests that the 2 methods of time diary administration

Table 6. Mean score difference in the number of occupational repertoires and verbatim between the participants of yesterday and tomorrow-diary groups

\begin{tabular}{cccc}
\hline Characteristic & Yesterday-Diary $(\mathbf{n}=\mathbf{1 1 6})$ & Tomorrow-Diary $(\mathbf{n}=\mathbf{1 2 1})$ & $\mathbf{P}$ \\
\hline Occupational repertoires & 118.83 & 119.18 & 0.969 \\
Verbatim & 120.51 & 117.55 & 0.739 \\
\hline
\end{tabular}


can be used interchangeably. Further investigations are required to make a comparison of yesterday and tomorrow methods of time diary in other age groups, and especially among children and adolescents.

\section{Ethical Considerations}

\section{Compliance with ethical guidelines}

This study was approved by the Ethics Committee of University of Social Welfare and Rehabilitation Sciences (code: IR.USWR.REC.1395.193). Also, We obtained written informed consent from children's parents before their participation.

Funding

This research was supported by Child Health Bureau, Ministry of Health and Medical Education of Iran.

\section{Authors contributions}

All authors contributed to this project and article. All authors read and approved the final manuscript.

\section{Conflict of interest}

The authors declared no conflict of interest.

Acknowledgements

We gratefully acknowledge the help provided by Dr. Hamed Barekati.

\section{References}

[1] Rees G. Children's activities and time-use: Variations between and within 16 countries. Children and Youth Services Review. 2017; 80:78-87. [DOI:10.1016/j.childyouth.2017.06.057]

[2] Sourtiji H, Rassafiani M, Hosseini SA, Mohammadian F [The relationship between the pattern of time-use and aspects of growth and development of children based on the levels of International Classification of Functioning (ICF) (Persian)]. Journal of Paramedical Sciences \& Rehabilitation. 2017; 6(3):86-98. [DOI:10.22038/JPSR.2017.14007.1297]

[3] Pentland WE, McColl MA. Application of time use research to the study of life with a disability. In: Pentland WE, Harvey As, Lawton P, McColl MA, editors. Time Use Research in the Social Sciences. Berlin: Springer; 2002. [DOI:10.1007/b107540]

[4] Sayyid Salman R, Farida F. Time-use surveys: Methods, uses and limitations. Interdisciplinary Journal of Contemporary Research in Business. 2011; 2(12):925.
[5] Krueger AB, Kahneman D, Fischler C, Schkade D, Schwarz $\mathrm{N}$, Stone AA. Time-use and subjective well-being in France and the US. Social Indicators Research. 2009; 93(1):7-18. [DOI:10.1007/s11205-008-9415-4]

[6] Kan MY, Pudney S. Measurement error in stylized and diary data on time-use. Sociological Methodology. 2008; 38(1):101 32. [DOI:10.1111/j.1467-9531.2008.00197.x]

[7] Juster FT, Ono H, Stafford FP. An assessment of alternative measures of time-use. Sociological Methodology. 2003 33(1):19-54. [DOI:10.1111/j.0081-1750.2003.t01-1-00126.x]

[8] Gershuny J. Time-use surveys and the measurement of national well-being. Oxford: Centre for Time-use Research; 2011

[9] Samaniego F, Nordhaus W, DaVanzo J, Bradburn N, Altonji J, Ver Ploeg M. Time-use measurement and research: Report of a workshop. Washington: National Academies Press; 2000.

[10] Dunham J. American time use: Who spends how long at what. New York: New Strategist; 2007.

[11] Marini MM, Shelton BA. Measuring household work: Recent experience in the United States. Social Science Research. 1993; 22(4):361-82. [DOI:10.1006/ssre.1993.1018]

[12] Schulz F, Grunow D. Comparing diary and survey estimates on time-use. European Sociological Review. 2011; 28(5):622-32. [DOI:10.1093/esr/jcr030]

[13] Division of Infectious Diseases. Guideline to producing statistics on time-use: Measuring paid and unpaid work. New York: Capacity Development United Nations; 2004.

[14] Juster FT. Response errors in the measurement of timeuse. Journal of the American Statistical Association. 1986; 81(394):390-402. [DOI:10.1080/01621459.1986.10478283]

[15] Chatzitheochari S, Fisher K, Gilbert E, Calderwood L, Huskinson $\mathrm{T}$, Cleary A, et al. Using new technologies for time diary data collection: Instrument design and data quality findings from a mixed-mode pilot survey. Social Indicators Research. 2017; 137(1):379-90.

[16] Sayer LC, Freedman VA, Bianchi SM. Gender, time-use, and aging. In: Binstock R, George Lk, editors. Handbook of Aging and the Social Sciences. Amsterdam: Elsevier; 2016. [DOI:10.1016/B978-0-12-417235-7.00008-1]

[17] Gersbuny J, Sullivan O. The sociological uses of time-use diary analysis. European Sociological Review. 1998; 14(1):6985. [DOI:10.1093/oxfordjournals.esr.a018228]

[18] Wright J. International encyclopedia of the social \& behavioral sciences. Amsterdam: Elsevier; 2015.

[19] Kelly P, Thomas E, Doherty A, Harms T, Burke Ó, Gershuny J, et al. Developing a method to test the validity of 24 hour time-use diaries using wearable cameras: A feasibility pilot. PLOS One. 2015; 10(12):e0142198. [DOI:10.1371/journal.pone.0142198] [PMID] [PMCID]

[20] Vikat A, Boko D. Guidelines for harmonising time use surveys. Geneva: Conference of European Statisticians; 2013.

[21] Naciones Unidas, United Nations Statistical Division Guide to producing statistics on time-use: Measuring paid and unpaid work. New York: United Nations Publications; 2005. 
[22] Gershuny J, Smith R. Report to the central statistical office on the development of a simple time diary schedule. ESRC Research Centre on Microsocial Change. Colchester: University of Essex; 1995. [PMID]

[23] Robinson JP. Time-diary research and human exposure assessment: Some methodological considerations. Atmospheric Environment. 1988; 22(10):2085-92. [DOI:10.1016/00046981(88)90120-5.]

[24] Robinson JP, Godbey G. Time for life: The surprising ways Americans use their time. Oxford: University Press; 1997.

[25] Belli RF, Alwin DF. Calendar and time diary methods in life course research. Thousand Oaks, California: Sage; 2009.

[26] Gershuny J, Harms T, Doherty A, Thomas E, Milton K, Kelly $\mathrm{P}$, et al. CAPTURE24: Testing self-report time-use diaries against objective instruments in real time. Oxford: University of Oxford; 2017.

[27] Jara Díaz S, Rosales Salas J. Understanding time-use: Daily or weekly data? Transportation Research Part A: Policy and Practice. 2015; 76:38-57. [DOI:10.1016/j.tra.2014.07.009.]

[28] Sonnenberg B, Riediger M, Wrzus C, Wagner GG. Measuring time-use in surveys- concordance of survey and experience sampling measures. Social Science Research. 2012; 41(5):1037-52. [DOI:10.1016/j.ssresearch.2012.03.013.]

[29] American Journal of Occupational Therapy. Occupational therapy practice framework: Domain and process. American Journal of Occupational Therapy. 2017; 68 (Suppl. 1): S1-S4. [DOI:10.5014/ajot.2014.682006]

[30] Robinson JP, Godbey G. Busyness as usual. Social Research: An International Quarterly. 2005; 72(2):407-26.

[31] Hunt E, McKay EA. A scoping review of time-use research in occupational therapy and occupational science. Scandinavian Journal of Occupational Therapy. 2015; 22(1):1-12. [DOI: 10.3109/11038128.2014.934918] [PMID] 